\title{
Baltic Sea climate: 200 yr of data on air temperature, sea level variation, ice cover, and atmospheric circulation
}

\author{
Anders Omstedt ${ }^{1, *}$, Christin Pettersen $^{1}$, Johan Rodhe $^{1}{ }^{\text {, Peter Winsor }}{ }^{2}$ \\ ${ }^{1}$ Department of Oceanography, Earth Sciences Centre, Göteborg University, 40530 Göteborg, Sweden \\ ${ }^{2}$ Physical Oceanography Department, Woods Hole Oceanographic Institution, Woods Hole, Massachusetts 02543, USA
}

\begin{abstract}
Relevant observed time series for the Baltic Sea region from the last 2 centuries were used to investigate climate variations and trends. These time series were: Stockholm air temperature and magnitude of seasonal temperature cycle, Stockholm sea level data, Baltic Sea maximum ice cover, and circulation types based on regional air pressure data. The definition of climate was analysed by considering how each parameter varies with the time scale. We found that $90 \%$ of the variance was for time scales shorter than $15 \mathrm{yr}$, the period then used as the climate-averaging time for all studied parameters. The results indicate positive trends for air temperature, sea level, and frequencies of anti-cyclonic circulation and westerly wind types over the last $200 \mathrm{yr}$. Negative trends were found for the magnitude of seasonal temperature cycle, sea-ice cover, and frequency of southwesterly wind. The major climate changes of the late 19th century were probably associated with the end of the 'Little Ice Age' and characterized by an unusual high frequency of cyclonic circulation. In the 20th century, pronounced positive trends were observed in sea level variation and anti-cyclonic circulation. In the most recent studied climate period (1985-2000), air temperature and sea level climate anomalies were positive and lay outside the range of last $200 \mathrm{yr}$ normal variations. The study indicates that increased frequencies of anti-cyclonic circulation and westerly winds have resulted in a slightly warmer climate with reduced seasonal amplitude and reduced ice cover. Thereby, we support the hypothesis that the long-term climate change in the Baltic Sea region is at least partly related to changes in the atmospheric circulation.
\end{abstract}

KEY WORDS: Baltic Sea · Climate - Atmospheric circulation · Temperature · Ice and sea levels Resale or republication not permitted without written consent of the publisher

\section{INTRODUCTION}

The Baltic Sea climate shows great variability in many parameters such as river runoff, salinity, sea level, and sea ice. The main reason for this is the location of the Baltic Sea between the North Atlantic and Eurasian weather systems, which leads to large seasonal and inter-annual variation in the low- and the high-pressure systems. The close relationship between large-scale atmospheric circulation and Baltic Sea climate variability is well documented (Tinz 1996, Chen \& Hellström 1999, Koslowski \& Glaser 1999, Jevrejeva 2001, Omstedt \& Chen 2001, Andersson 2002). Over time scales longer than $1 \mathrm{yr}$ the Baltic Sea is almost in thermodynamic balance with the atmosphere (Omstedt \& Rutgersson 2001). The water balance, however, involves longer times scales: fresh-water inflow variations are associated with time scales of several decades (Winsor et al. 2001). The difference in time scales implies that regional climate-change signals will likely be observed first in parameters closely related to the heat balance rather than to the water balance.

Man-made (stemming from increased greenhouse gases and troposphere sulphate aerosols) versus natural climate change (including changes in volcanic and solar forcings) is one of the central scientific discussions in climate research today. Several studies have found long-term changes in certain elements of the 
current climate (Heino et al. 1999, Crowley 2000, IPCC 2001), and some authors claim that warming since 1975 is likely to be partly due to increased amounts of greenhouse gases (Karlén et al. 1999, IPCC 2001). Similar warming may also have happened during the Medieval Warm Period (Crowley \& Lowery 1999). Recent research using tree-ring-based chronologies indicates that the variability of recent decades may lies within the natural range (Esper at al. 2002). This illustrates the difficulty of climate research. Also, probability views based on studies using general circulation models (GCMs) may be questionable, as they often only resolve atmospheric circulation coarsely and exclude realistic treatment of some forcing mechanisms (Räisänen \& Alexandersson 2003).

It is often difficult to attribute a given change to a particular mechanism, and equally difficult to distinguish between trends and oscillations. It is, for example, an oversimplification to explain observed hemisphere mean surface warming by direct greenhouse forcing, as part of the increase could be associated with a change in circulation (Corti et al. 1999). Trend interpretation can also be suspect when analysing periods that include significant regime shifts such as the Little Ice Age (Omstedt \& Chen 2001). The latter paper indicates that the decrease in the maximum ice cover in the Baltic Sea is associated with a significant regime shift in the late 19th century, from a relatively cold climate regime (Little Ice Age) to a relatively warm one.
This event was also documented by analysing longterm variations of sea level at Stockholm (Ekman 1999). Perhaps one of the most important aspects in climate research is to analyse the climate signature of regime shifts and understand the dynamics of the regimes change (Stewart 2003).

A characterisation of the Baltic Sea climate and associated trends is the focus of this paper. Using long-term data sets, we examine whether recent observations lie outside the range of normal variation in the last $200 \mathrm{yr}$ and whether these could be attributed to changes in atmospheric circulation or anthropogenic forcing.

The current study examines climatic conditions in the Baltic Sea region (Fig. 1) over the last 200 yr. A number of interesting long-term time series are available in the region, but this study is restricted to some well-documented ones, examining their properties in terms of climate and their interrelationships with atmospheric circulation. These data consist of Stockholm air temperature and sea level records, Baltic Sea maximum ice cover record, and regional air-pressure indices characterising the atmospheric circulation types.

Section 2 presents the data used in the study. Section 3 examines variability in the investigated time series and how to define the concept of climate. Statistics and trends are presented in Section 4, and interrelations between variables and atmospheric circulation types are examined in Section 5. Section 6 presents a summary and some conclusions.

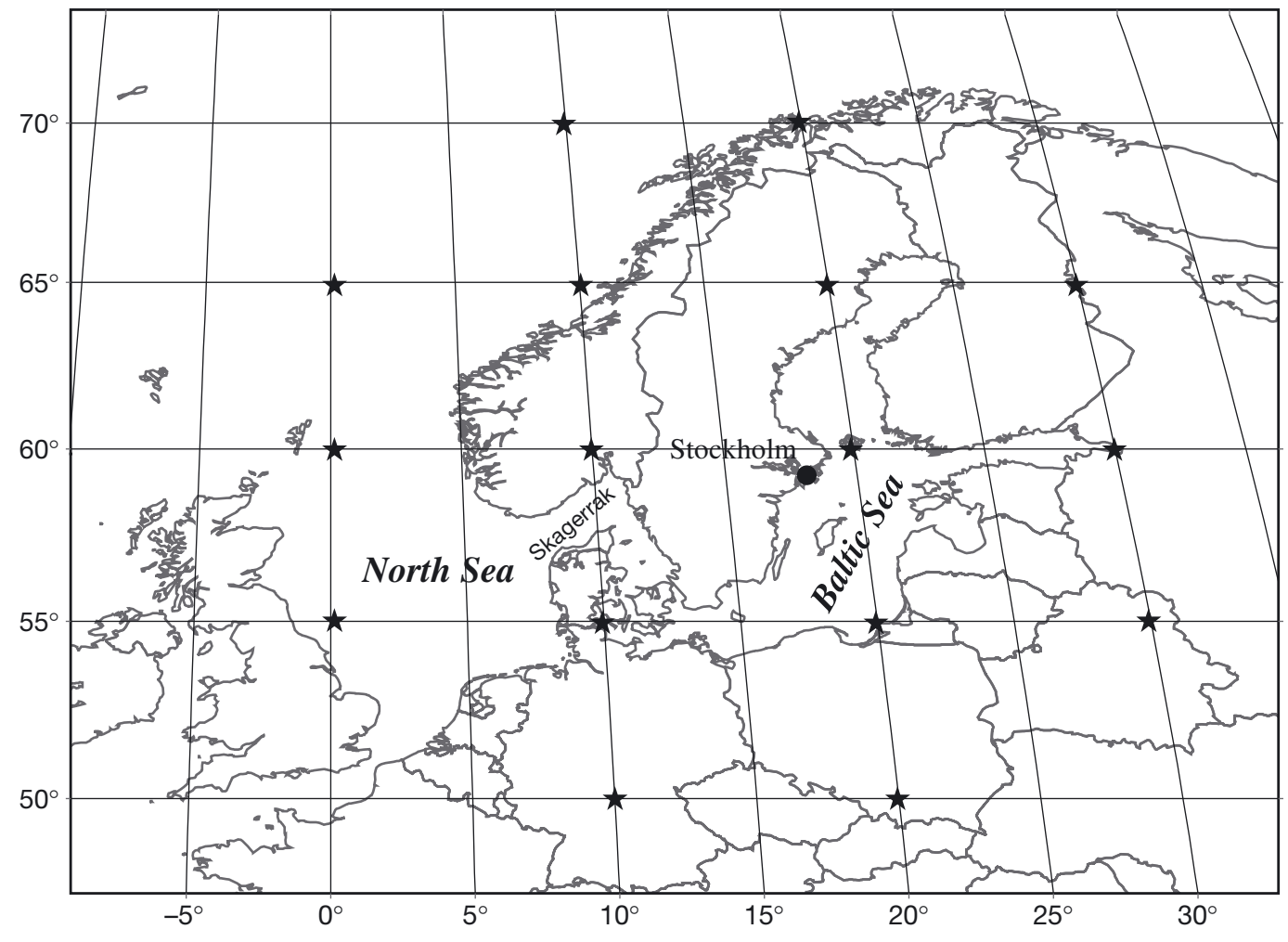

Fig. 1. The Baltic Sea and Skagerrak system. Stars indicate the pressure points used when calculating the circulation indices 
Table 1. Data used in the analysis

\begin{tabular}{|lllll|}
\hline Parameter & Site or region & Period & Time resolution & Source \\
\hline Air temperature & Stockholm & $1756-2000$ & Monthly & Moberg \& Bergström (1997) \\
Sea levels & Stockholm & $1825-2000$ & Monthly & Ekman (1999) \\
Max. ice cover & Baltic Sea & $1720-2000$ & Annual & Seinä \& Palosuo (1993) \\
Circulation types & Northern Europe & $1775-2000$ & Monthly & Chen (2000) \\
\hline
\end{tabular}

\section{MATERIAL AND BASIC STATISTICS}

The data used for this statistical analysis are summarised in Table 1 and illustrated in Fig. 2. For air temperature, monthly data from Stockholm are used. This time series is one of the longest available from the Baltic Sea area and Sweden. Monthly means have been carefully checked and homogenised by Moberg \& Bergström (1997), and they are now available for 1756-2000 as daily values (Moberg et al. 2002). From this record we have calculated the difference between the summer (JJA) and winter (DJF) seasonal temperatures as a measure of the magnitude of the annual temperature cycle.

The sea level data used in this study are from Stockholm and were detrended by eliminating postglacial land uplift using a linear regression model (4.92 mm $\mathrm{yr}^{-1}$ ) based on data from 1774-1884 (Ekman 1999).

The ice data used were collected by the Finnish Institute of Marine Research, whose method is described by Seinä \& Palosou (1993). The data have been analysed in several studies and the reader is referred to Omstedt \& Chen (2001) for further information.

In analysing atmospheric circulation we used circulation indices or classifications of circulation types. These indices follow those of Lamb (1950), and the calculations and the scheme were adapted to the Baltic Sea by Chen (2000). In this study, the same scheme was used to calculate the circulation indices which were then used to classify the circulation types for each month. The sea level pressure data at the 16 points were derived from a data set developed by ADVICE
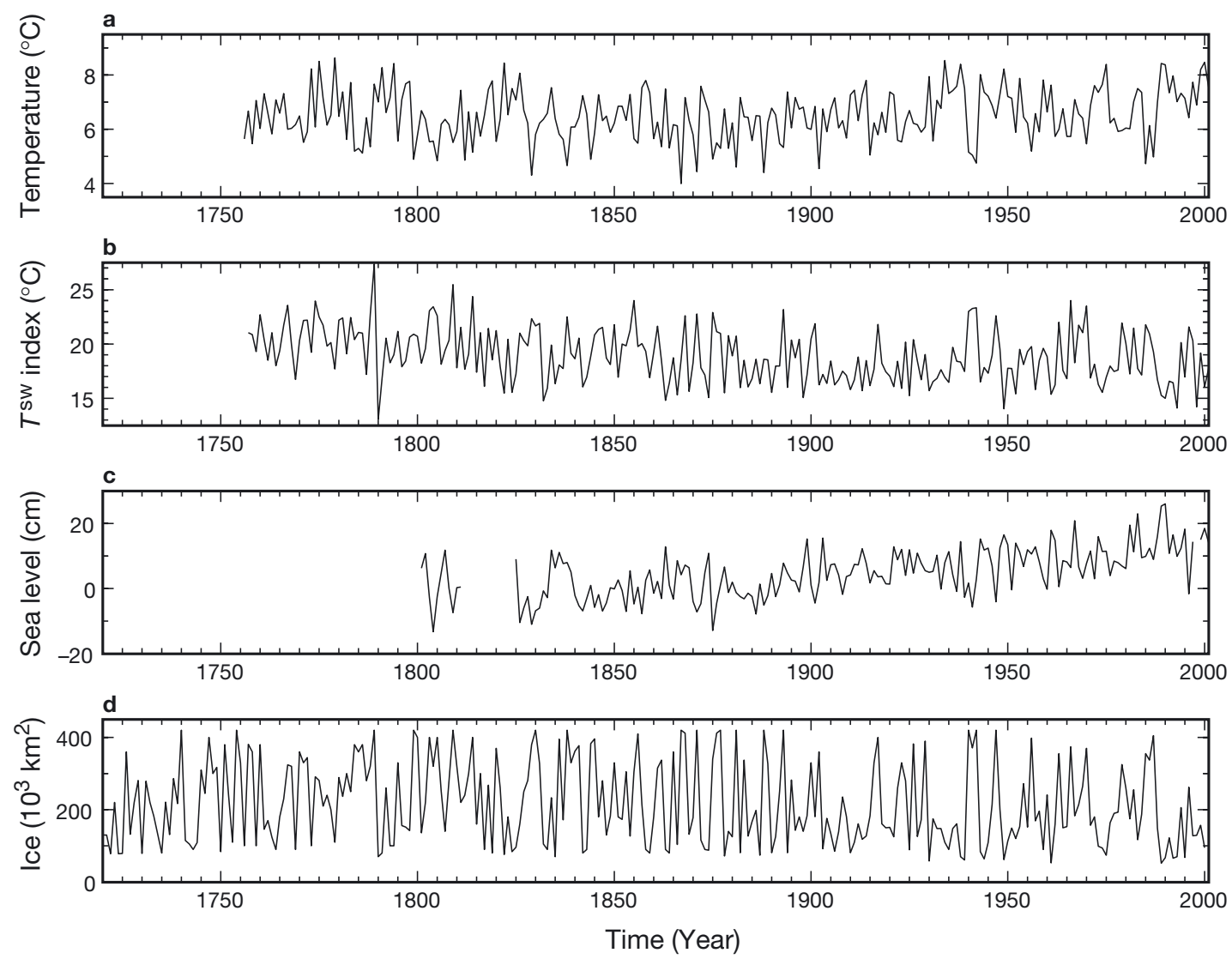

Fig. 2. Time series showing (a) air temperature, (b) magnitude of the seasonal air temperature cycle ( $T^{\mathrm{sw}}$ index), (c) sea level (all from Stockholm), and (d) maximum annual ice cover for the Baltic Sea 
project (e.g. Jones et al. 1999). The pressure grid used when calculating the indices is illustrated in Fig. 1.

We have used basic statistical methods to organise, summarise, and present our time series. In the time series we use monthly means, yearly means, and means over longer time periods. They were calculated as sample means (sums of all values in the record divided by the number of values), running means (sums of all values in a given period divided by the number of values in the given period), and seasonal means (sums of all values for each month divided by the number of values in each month). Maximum and minimum values for a given time period were calculated as well as variance (arithmetic mean of the squared deviation from the mean), normalised variance (variance for different time intervals divided with the variance of the full record), and standard deviation (the positive square root of the variance). For trend analysis we calculated the trend as the slope of the linear regression equation.

\section{CLIMATE AND VARIABILITY}

A climate time scale is the period over which we average a given variable, for example, air temperature, when discussing climate change. The number of years to include in this period depends on in what relation we wish to discuss climate variation and on the resolution of the time series to be used. The current study uses modern observations, limiting us to a time series of about $200 \mathrm{yr}$. The upper limit is thus $100 \mathrm{yr}$ for discussing changes, while the lower limit is $1 \mathrm{yr}$. It is common to use averages over $30 \mathrm{yr}$, with the period 1961-1990 taken as the latest standard period. To look closer into the definition of climate time scale, we analysed the time series to arrive at an objective measure of a climatic relevant time scale. Fig. 3 shows how the variance of the different time series depends on the number of years over which the series is averaged. The variance is normalised such that the variance is 1 for a resolution of 1 yr. Note that the relative variance drops rapidly when the averaging time increases above 1 yr. All variables, except for sea level, behave in a similar fashion. In the region of a $15 \mathrm{yr}$ averaging time, the curves flatten out at a level below 0.1 , indicating that $90 \%$ of the variance is found in time scales shorter than 15 yr. In light of this, we suggest that $15 \mathrm{yr}$ is an appropriate climateaveraging time, and this period was used in the study. The similarities between the variance of the different variables indicate a close interrelation between their variations, especially over the short time scales. Their variations could probably be related to variations of the same forcing. It is also indicated that their internal response time is shorter than or as large as the time scale of the variation of the forcing.

Why does sea level variance differ from that of the other variables? It could be that sea level variation is partly related to another force, or that the response time for sea level variation is longer. Fig. 3 presents the effects of a climate trend associated with a rise in sea level driven externally and not originating within the Baltic Sea basin itself. After detrending the sea level data with a sea level rise equal to $1 \mathrm{~mm} \mathrm{yr}^{-1}$ from 1900 to 2000 , the sea level variability follows the other parameters much more closely. This rate of sea level rise is close to the global estimate of $1.5 \pm 0.5 \mathrm{~mm} \mathrm{yr}^{-1}$ (IPPC 2001, p. 665). Earlier findings suggest that external sea level signals of $1 \mathrm{mo}$ or longer in duration penetrate the Baltic Sea without noticeable damping (Samuelsson \& Stigebrandt 1996, Wroblewski 1998). This result suggests that changes in Stockholm sea level variation over the last 100 yr are mainly externally driven from outside the Baltic Sea entrance.

To illustrate the importance of choosing the appropriate climate time period, Stockholm air temperature is shown in Fig. 4 using different averaging periods. It is clear that variability is considerably reduced by increasing the averaging period, but whether 15 or $30 \mathrm{yr}$ averaging is used makes little difference. Based on the variance study, we have defined the climate time period as $15 \mathrm{yr}$. We used discrete $15 \mathrm{yr}$ periods

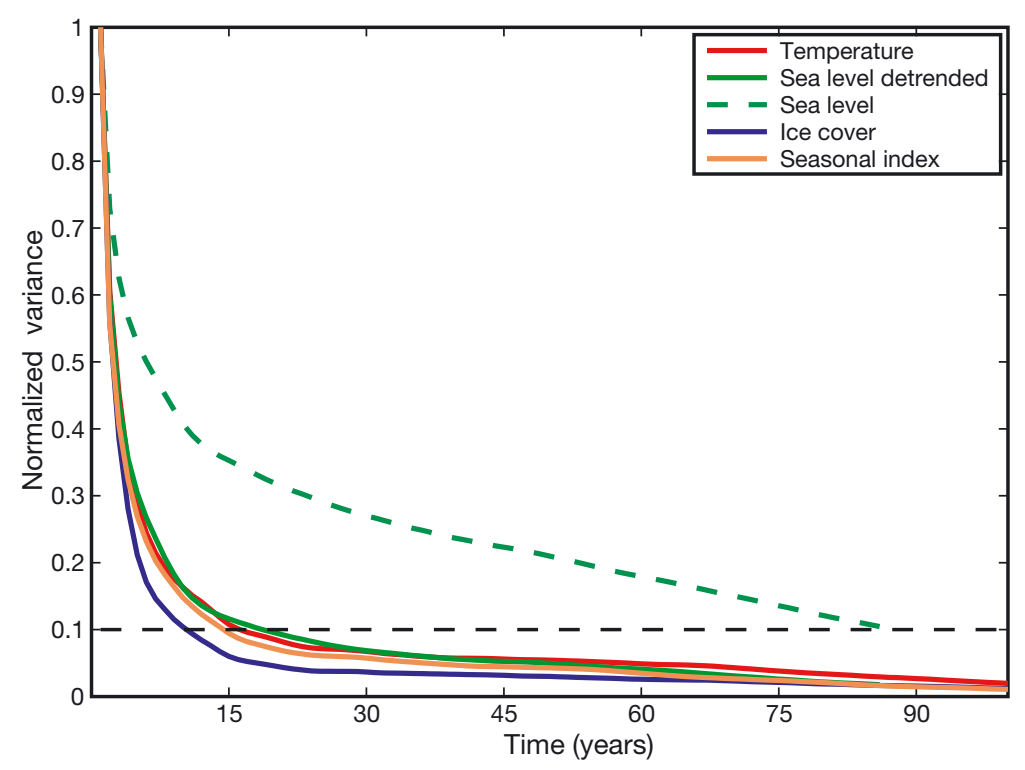

Fig. 3. Normalised variance of the studied time series 
Fig. 4. Time-averaged air temperatures from the Stockholm record using different running means

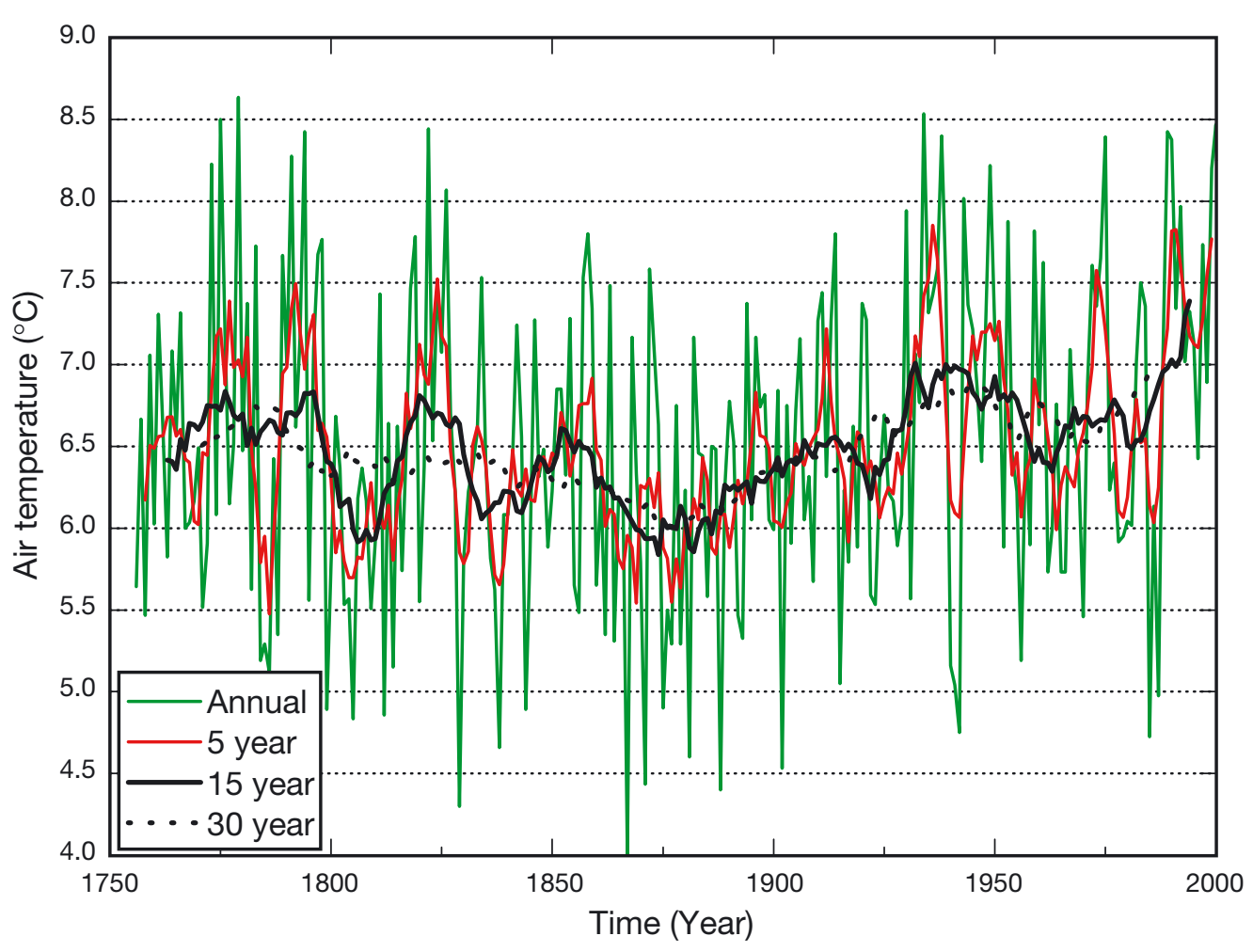

and analysed how their statistical properties vary from the beginning of the 19th century to the present, and how these properties relate to atmospheric circulation. We want to follow standard meteorological climate periods as closely as possible, choosing periods such that 1961-1990 coincides with 2 of our $15 \mathrm{yr}$ climate periods. Unfortunately, this leaves 2 periods of only $10 \mathrm{yr}$ each at either end of the time series. However, we include these periods as overlapping $15 \mathrm{yr}$ periods in order to be able to include the first $15 \mathrm{yr}$ of the 19th century and the last $15 \mathrm{yr}$ of the 20th century in the discussion. The climate periods used are thus: 1800-1815, 1811-1825, 1826-1840, ..., 1961-1975, 1976-1990, 1986-2000. If other periods are used, different trends will be found. We therefore examine both $100 \mathrm{yr}$ and 200 yr trends.

\section{STATISTICS}

This section treats the anomalies and trends of the different variables, one by one. Our basic interests are the following:

- What can we learn from the statistics in relation to climate means and variability?

- What are the statistical differences between the 19th and the 20th centuries?

- How large is the climate change over this period, and does the late 20th century exceed the normal climatic variability of the last $200 \mathrm{yr}$ ?
The climatic variability and trends evident in $200 \mathrm{yr}$ of Stockholm temperature records appear in Fig. 5. The climate mean temperature for the whole period is $6.5^{\circ} \mathrm{C}$, and the mean temperatures show a clearly positive trend, with the last decade standing out as unusually warm. The increase in the climate mean temperature starts at the beginning of the 20th century, as did the increase in maximum air temperatures. However, high maximum temperatures were also recorded at the beginning of the 19th century. The climate minimum temperatures were lowest in the mid 19th century. No clear trend can be discerned in either the maximum or minimum temperatures or in their variance. The statistical trend is drawn as a linear trend over the whole period, but closer inspection indicates that the 19th and 20th centuries behaved differently.

The climate and climate change of the magnitude of the annual temperature cycle appear in Fig. 6. For a large index we would expect a more continental climate influence, while a smaller index would indicate a stronger maritime influence. The magnitude of the annual cycle is $18.6^{\circ} \mathrm{C}$, with a decreasing trend. The figure indicates that in the 19th century up to 1850 the magnitude of the annual cycle was larger; thereafter, the amplitude decreased, beginning mainly in 1900 and at the end of the period studied. Both the maximum and minimum magnitudes of the annual cycle indicate trends towards lower maximum and minimum seasonal amplitudes, respectively. 

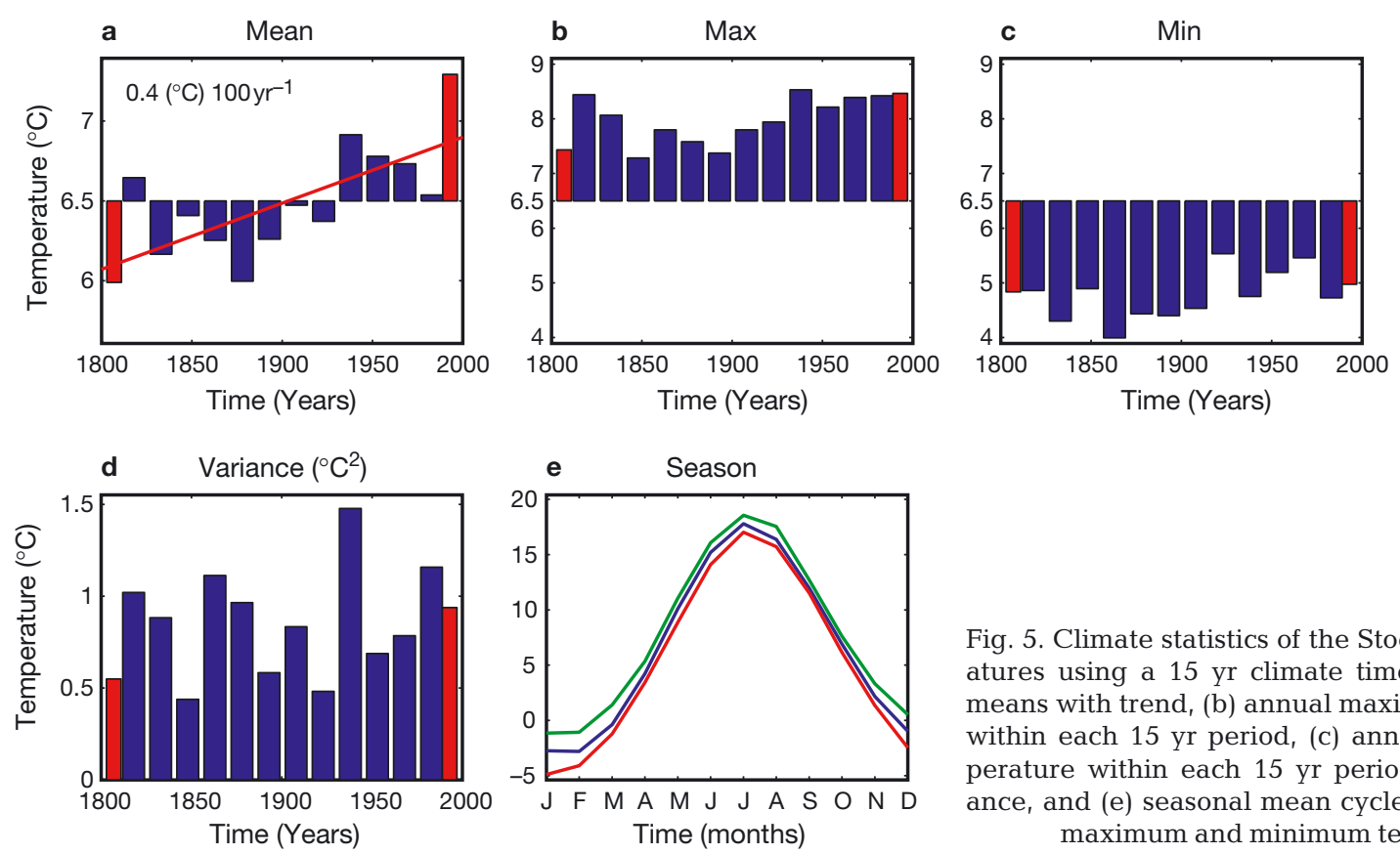

Fig. 5. Climate statistics of the Stockholm air temperatures using a $15 \mathrm{yr}$ climate time period. (a) $15 \mathrm{yr}$ means with trend, (b) annual maximum temperatures within each $15 \mathrm{yr}$ period, (c) annual minimum temperature within each $15 \mathrm{yr}$ period, (d) annual variance, and (e) seasonal mean cycle with $15 \mathrm{yr}$ annual maximum and minimum temperatures

The Stockholm sea level record is shown in Fig. 7. The mean sea level is $5.3 \mathrm{~cm}$, and we discern a positive trend in mean, maximum, and minimum sea levels. The difference between the 19th and 20th centuries is also obvious, as is the fact that the sea level during the last climate period was the highest in the record.

The corresponding results for ice cover are shown in Fig. 8, where the mean value is $212 \times 10^{3} \mathrm{~km}^{2}$, with a decreasing trend evident. No trend is observed in the maximum values, but there is a negative trend in the minimum values. The maximum ice limit is controlled by the Kattegat-Skagerrak water front that divides the surface water into a cold, brackish layer originating in the Baltic Sea and a warmer, more saline layer originating from the Skagerrak Sea. The maximum values have thus not changed over the last $200 \mathrm{yr}$, indicating that the Kattegat-Skagerrak front is a permanent regional limit for the ice. The decrease in minimum ice cover could be due to the fact that ice maps have
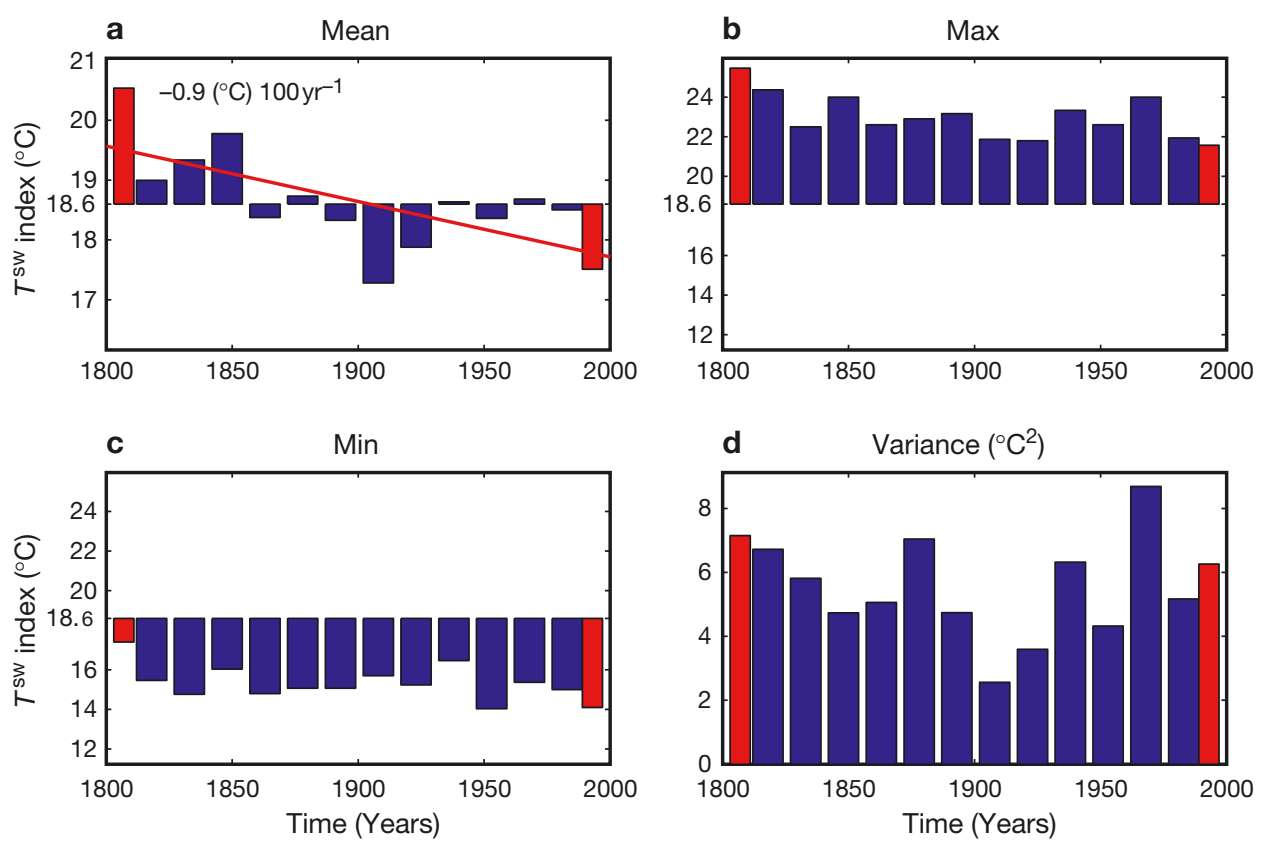

Fig. 6. Climate statistics of the magnitude of the seasonal Stockholm air temperature cycle, $T^{\mathrm{sw}}$ index, using a 15 yr climate time period. (a) 15 yr means with trend, (b) maximum seasonal cycle within each $15 \mathrm{yr}$ period, (c) minimum seasonal cycle within each $15 \mathrm{yr}$ period, and (d) variance within each $15 \mathrm{yr}$ period 

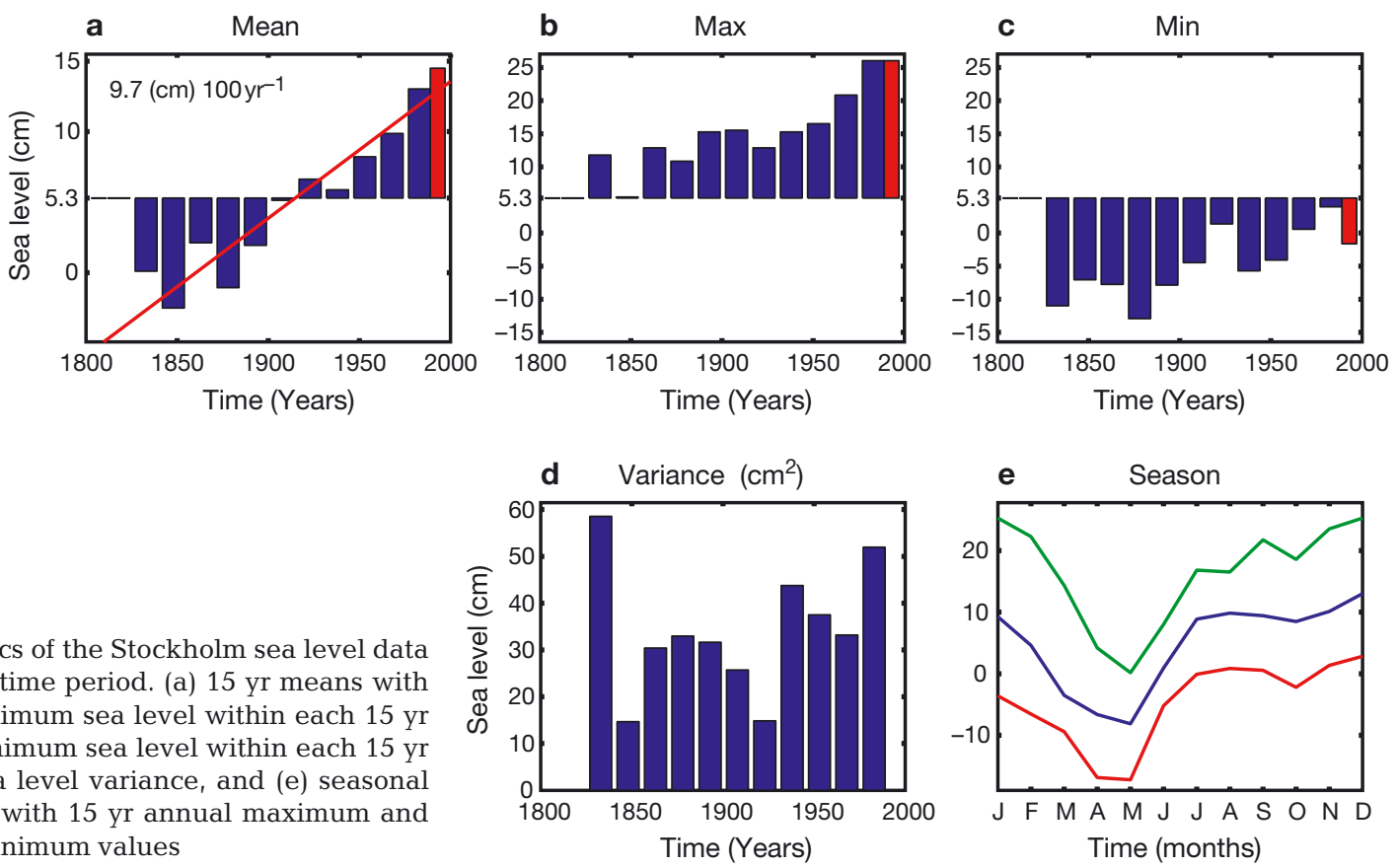

Fig. 7. Climate statistics of the Stockholm sea level data using a $15 \mathrm{yr}$ climate time period. (a) $15 \mathrm{yr}$ means with trend, (b) annual maximum sea level within each $15 \mathrm{yr}$ period, (c) annual minimum sea level within each $15 \mathrm{yr}$ period, (d) annual sea level variance, and (e) seasonal mean sea level cycle with $15 \mathrm{yr}$ annual maximum and minimum values

improved in accuracy over the last few decades. Another interpretation is that the decrease in minimum ice cover is due to regional warming. The variance of sea ice cover indicates highest values during the period 1871-1885.

Fig. 9 presents the frequency of the major circulation types averaged over $15 \mathrm{yr}$ periods. A large number of different types were calculated (27 different types) but 4 types dominate, namely the westerly (W), southwesterly (SW), anti-cyclonic (A), and cyclonic (C) types.
Together they account for $59.2 \%$ of the whole studied period. The change of dominant circulation types is presented in Fig. 10, and we can observe that anticyclonic circulation has increased, while cyclonic circulation has decreased. Also that in the end of 19th century there was unusual high frequency of cyclonic circulation. The maximum frequency of cyclonic circulation (1871-1885) appears around the time identified by Omstedt \& Chen (2001) as a climate change point associated with the end of the Little
Fig. 8. Climate statistics of the annual maximum ice cover for the Baltic Sea using a 15 yr climate time period. (a) 15 yr means with trend, (b) maximum ice cover within each $15 \mathrm{yr}$ period, (c) minimum ice cover within each $15 \mathrm{yr}$ period, and (d) variance
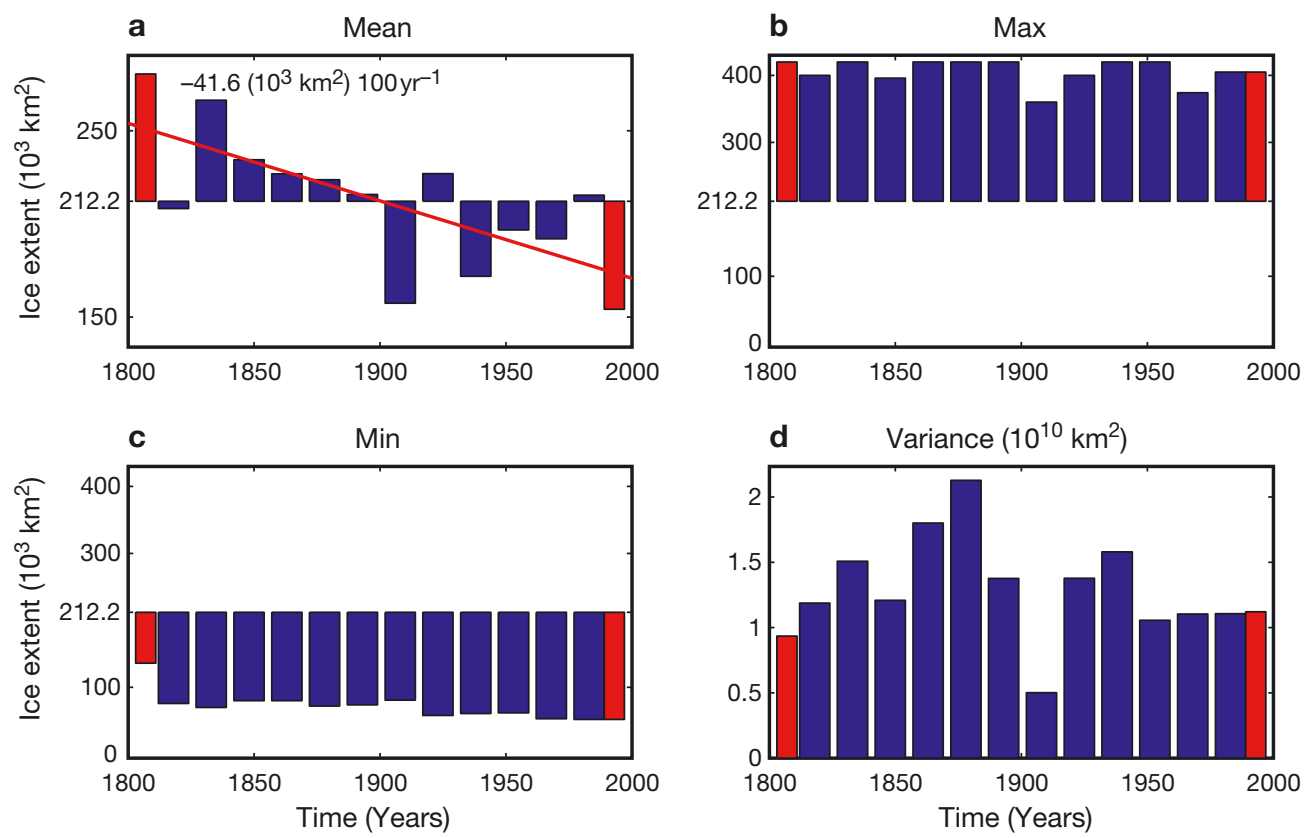


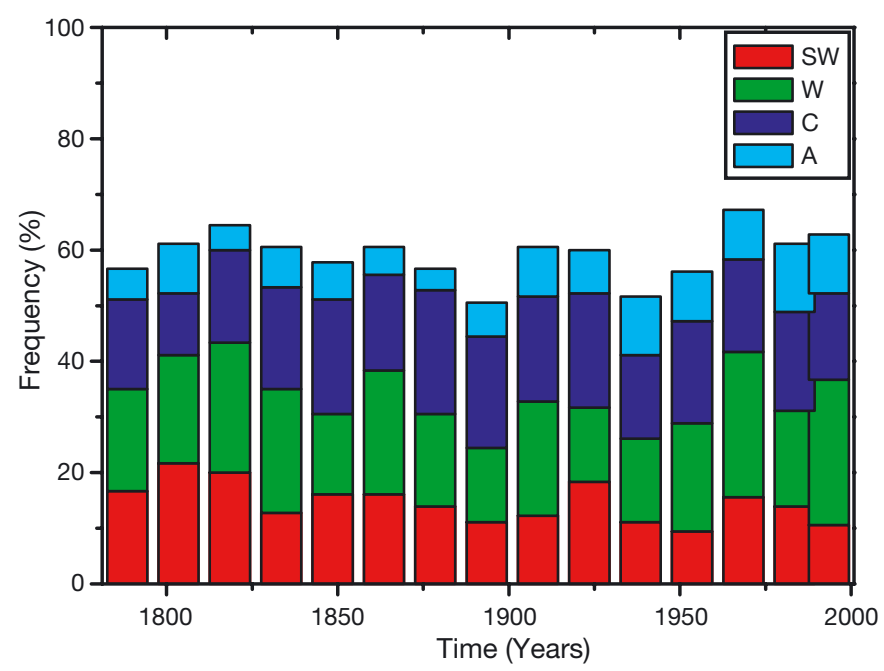

Fig. 9. Frequency changes of the 4 major circulation types from 1800-2000. W: westerly; SW: southwesterly; A: anticyclonic; C: cyclonic

Ice Age. Westerly winds have increased, while southwesterly ones have decreased. To understand whether these changes are large or small, we should note that, for example, anti-cyclonic circulation increased starting from the beginning of 19th century to the end of 20 th by $14 \mathrm{mo}$, or about $8 \%$. The increased anticyclonic circulation can be compared with the recent work by Jacobeit et al. (2003). They found a strong increase in winter-time westerly circulation over the last few decades, and a general increase of anticyclonic conditions, strengthening in July, over the last $50 \mathrm{yr}$.

Table 2 reveals that the 2 centuries differ in several ways. The 19th century saw trends toward slight cooling, reduced magnitude of the seasonal cycle, a slight increase in sea level, and a clear reduction in ice cover. This is in contrast to the 20th century, when there were trends toward increased air temperature, slightly increased magnitude of the seasonal cycle, increased sea level, and only a slight decrease in ice cover.

The major climate changes occurred at the end of the 19th century probably associated with the end of the Little Ice Age. Over the 20th century positive trends have been evident, particularly in terms of sea level variation and anti-cyclonic and westerly wind circulation types. In the most recent studied climate period (1986-2000), air temperature and sea level climate anomalies have been positive and are the largest of the studied period.

\section{INTERRELATIONS}

Several studies treat the interrelations of the parameters analysed in this work. Chen \& Hellström (1999) examined the influence of NAO on regional air temperature. Chen (2000) examined winter air temperatures in relation to monthly circulation climatol-
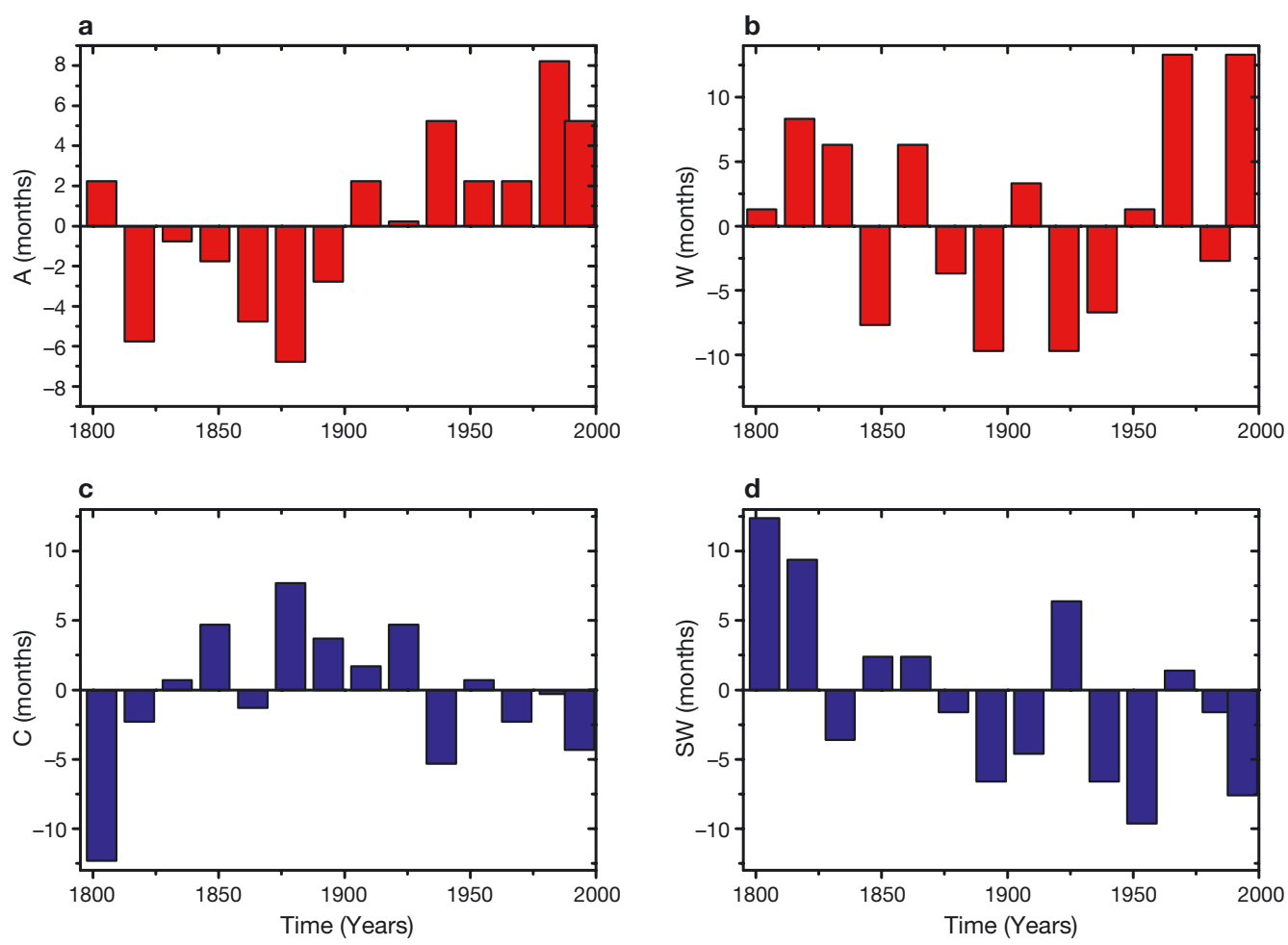

Fig. 10. Frequency anomalies of the 4 major circulation types. (a) anti-cyclonic type A, (b) westerly type $\mathrm{W}$, (c) cyclonic type $\mathrm{C}$, and (d) southwesterly type SW 
Table 2. A statistical comparison between the 19th and 20th centuries

\begin{tabular}{|lcc|}
\hline Parameter & $1801-1900$ & $1901-2000$ \\
\hline Mean temperature & $6.3^{\circ} \mathrm{C}$ & $6.7^{\circ} \mathrm{C}$ \\
Temperature trend & $-0.1^{\circ} \mathrm{C} \mathrm{century}^{-1}$ & $0.7^{\circ} \mathrm{C}$ century \\
Temperature variance & $0.79^{\circ} \mathrm{C}^{2}$ & $0.90^{\circ} \mathrm{C}^{2}$ \\
Mean temperature index & $19.1^{\circ} \mathrm{C}$ & $18.2^{\circ} \mathrm{C}$ \\
Temperature-index trend & $-2^{\circ} \mathrm{C} \mathrm{century}^{-1}$ & $0.7^{\circ} \mathrm{C} \mathrm{century}$ \\
Temperature-index variance & $6.03^{\circ} \mathrm{C}^{2}$ & $5.22^{\circ} \mathrm{C}^{2}$ \\
Mean sea level & $0.3 \mathrm{~cm}$ & $8.5 \mathrm{~cm}^{-1}$ \\
Sea level trend & $1.8 \mathrm{~cm} \mathrm{century}^{-1}$ & $9.9 \mathrm{~cm} \mathrm{century}^{-1}$ \\
Sea level variance & $37.51 \mathrm{~cm}^{2}$ & $41.05 \mathrm{~cm}^{2}$ \\
Mean ice cover & $235.2 \times 10^{3} \mathrm{~km}^{2}$ & $187.1 \times 10^{3} \mathrm{~km}^{2}$ \\
Ice cover trend & $-47.6 \times 10^{3} \mathrm{~km}^{2} \mathrm{century}^{-1}$ & $-10.1 \times 10^{3} \mathrm{~km}^{2} \mathrm{century}^{-1}$ \\
Ice cover variance & $1.46 \times 10^{4}\left(10^{3} \mathrm{~km}^{2}\right)^{2}$ & $1.08 \times 10^{4}\left(10^{3} \mathrm{~km}^{2}\right)^{2}$ \\
\hline
\end{tabular}

various circulation indices and parameters from the Baltic Sea region, such as temperature, ice cover, and sea levels.

This section will not repeat those studies by using, for example, multiregression methods to link the various time series. Instead, we will try to interpret our results and build a conceptual understanding that later can be validated by regional climate models. It is important to recognise that we are analysing 15 yr means. We are not analysing short-term weather history or seasonal changes, but with something more closely related to climate

ogy. Jacobeit et al. (2001) studied the relationship between circulation indices and temperature. Omstedt \& Chen (2001) related maximum ice cover to atmospheric winter circulation, and Gustafsson \& Andersson (2001) developed a model for sea level variation using pressure differences. The message from these studies is that there is a close inter-relation between atmospheric circulation as interpreted by
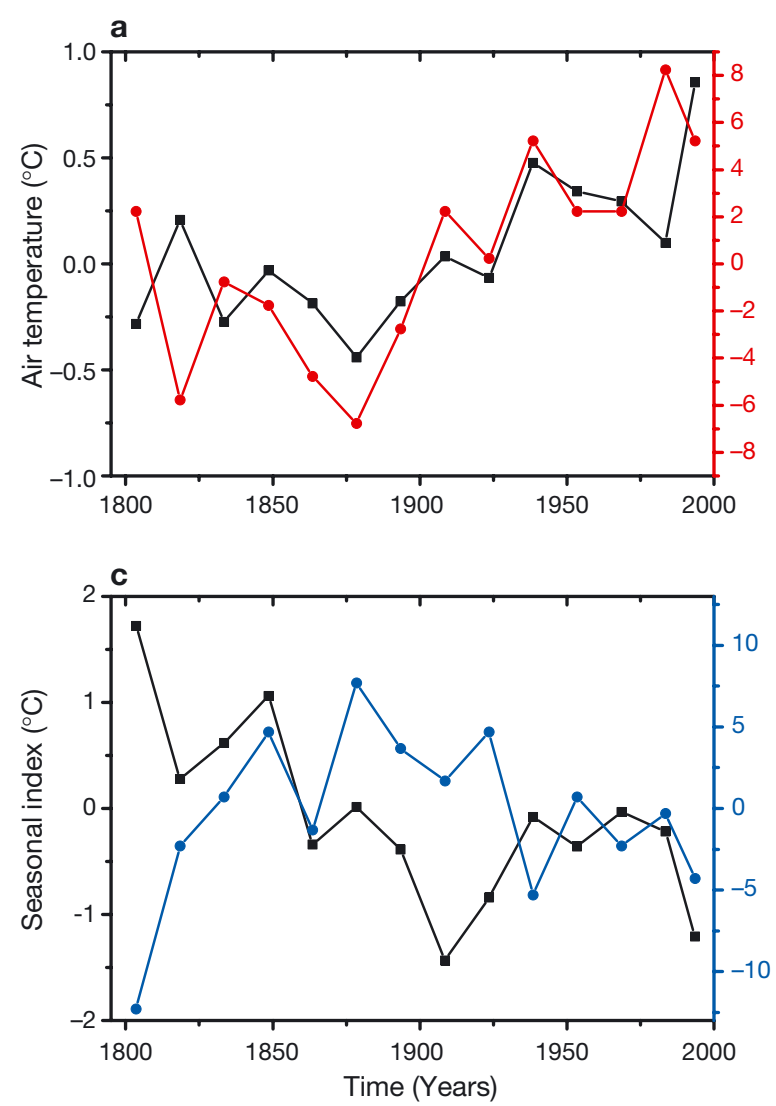

maps and how these depend on what climate period one uses as background information.

Figs. 11 \& 12 illustrate some interesting interrelations. The increase in air temperature and sea level anomalies closely follows the increased anti-cyclonic circulation type, while the change in magnitude of the seasonal temperature cycle and ice cover closely follows the reduced southwesterly wind type. The cli-
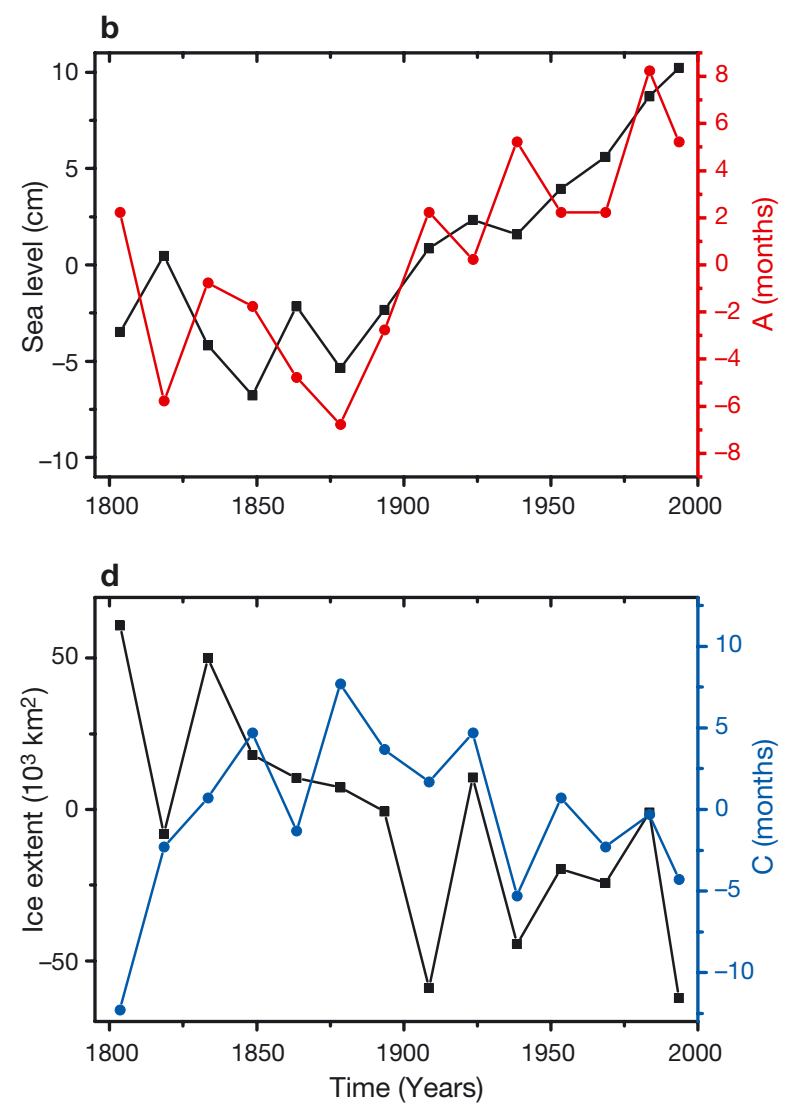

Fig. 11. Anomalies for the climate records together with the circulation types that describes the rotation of the atmospheric circulation. Red indicates anti-cyclonic and blue cyclonic circulation. (a) Air temperatures and anti cyclonic circulation; (b) sea level and anti cyclonic circulation; (c) seasonal index and cyclonic circulation; and (d) ice cover and cyclonic circulation 

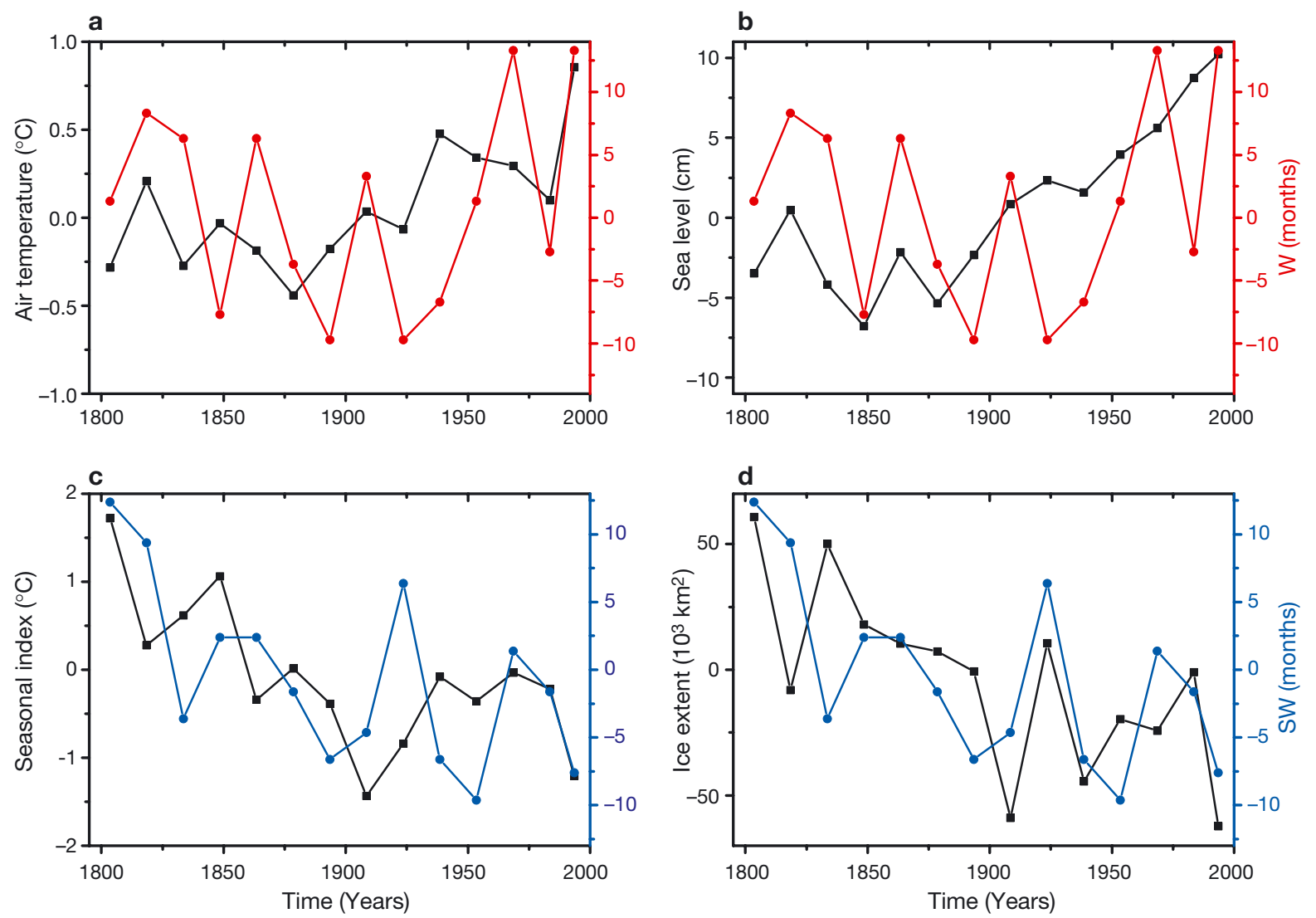

Fig. 12. Anomalies in the climate records together with the circulation types that describes the translation of the atmospheric circulation. Red indicates westerly and blue southwesterly flows. (a) Air temperatures and westerly flow; (b) sea level and westerly flow; (c) seasonal index and southwesterly flow; and (d) ice cover and southwesterly flow

mate-change pattern revealed by the 15 yr means over the last 200 yr indicates that the Baltic Sea climate has become more influenced by anti-cyclonic circulation. In other words, the low-pressure tracks have moved slightly northward, which is consistent with the observed upward trend in the NAO index and the changes in July and January circulation as reported by, for example, Hurell \& Folland (2003) and Jacobeit et al. (2003).

The study indicates that the increased frequency of anti-cyclonic circulation and increased westerly winds have resulted in a slightly warmer climate with a reduced magnitude of seasonal temperature cycle and reduced ice cover. The increased sea level variation in the Baltic Sea can probably partly be explained by a global sea level rise but also by the change in circulation. Since atmospheric circulation is central to the Baltic Sea climate, one could argue that the observed changes result entirely from atmospheric circulation and natural variability. This view, however, ignores the possibility that anthropogenic climate change may influence the large-scale atmospheric circulation. How changes in atmospheric circulation and anthropogenic forcing influences the Baltic Sea region remains a central research question, where climate models are needed.

\section{SUMMARY AND CONCLUSIONS}

This paper has addressed certain aspects of climate in the Baltic Sea region. Based on a selection of important Baltic Sea time series, we conducted a statistical analysis of regional climate and climate change over the last 2 centuries. The definition of climate was objectively analysed by considering how the variance of each parameter varies with the time scale. It was found that $90 \%$ of the variance occurs over time scales shorter than $15 \mathrm{yr}$, which determined our definition of the climate-averaging time. Long-term time series of air temperature, the magnitude of the seasonal air temperature cycle, sea level data, the Baltic Sea maximum ice cover, and circulation types based on air-pressure data over the Baltic region were examined, and some basic statistical aspects of the $15 \mathrm{yr}$ climate data were investigated. 
The main conclusions may be summarised as follows:

- Climate change over the last 200 yr manifests positive trends for air temperature, sea levels, and frequency of anti-cyclonic circulation and westerly wind types. Negative trends were found for the magnitude of the seasonal temperature cycle, sea-ice cover, and frequency of southwesterly wind types.

- From variance calculations using the Stockholm sea level time series, detrended by eliminating postglacial uplift, a positive trend associated with time scales longer than $15 \mathrm{yr}$ and forced changes outside the region was identified.

- Major climate changes occurred at the end of the 19th century, probably associated with the end of the Little Ice Age and identified as a period with an unusual high frequency of cyclonic circulation. During the 20th century positive trends have in particular been found in sea level and anti-cyclonic types. In the most recent studied climate period (1986-2000), air temperature and sea level anomalies were positive and lay outside the range of normal variations over the last 200 yr.

- Part of the major climate changes observed in the Baltic Sea region during the late 20th century can be related to changes in atmospheric circulation.

The study suggests that the increased frequency of anti-cyclonic circulation and westerly wind types have resulted in a slightly warmer climate with reduced seasonal amplitude and reduced ice cover. The increased sea level variation in the Baltic Sea can partly be explained by global rise in sea levels and partly by change in atmospheric circulation. Thereby, we support the hypothesis that the long-term climate change in the Baltic Sea region is at least partly related to changes in the atmospheric circulation.

Acknowledgements. This work is a part of the GEWEX/BALTEX and the SWECLIM programmes, and it has been funded by Göteborg University, the Swedish Research Council (Contract G 600-335/2001), MISTRA and SMHI within the Swedish SWECLIM programme. Financial support was also provided to P.W. by the Postdoctoral Scholar Program at the Woods Hole Oceanographic Institution, with funding provided by the Swedish Foundation for International Cooperation in Research and Higher Education (STINT) and the J. Seward Johnson Fund. We would also like to thank A. Moberg for providing the ADVICE data and D. Chen for programming and calculation of the circulation frequency changes.

\section{LITERATURE CITED}

Andersson HC (2002) Influence of long-term regional and large-scale atmospheric circulation on the Baltic sea level. Tellus 54A:76-88

Chen D (2000) A monthly circulation climatology for Sweden and its application to a winter temperature case study. Int J Climatol 20:1067-1076

Chen D, Hellström C (1999) The influence of the North Atlantic Oscillation on the regional temperature variability in Sweden: spatial and temporal variations. Tellus 51A:505-516

Corti S, Molteni F, Palmer TN (1999) Signature of recent climate change in frequencies of natural atmospheric circulation regimes. Nature 398:799-802

Crowley TJ (2000) Causes of climate change over the past 1000 years. Science 289:270-277

Crowley T, Lowery TS (1999) How warm was the medieval warm period? Ambio 29:51-54

Ekman M (1999) Climate changes detected through the world's longest sea level series. Global Planet Change 21:215-224

Esper J, Cook ER, Schweingruber FH (2002) Low-frequency signals in long tree-ring chronologies for reconstructing past temperature variability. Science 295:2250-2253

Gustafsson BG, Andersson HC (2001) Modeling the exchange of the Baltic Sea from the meridional atmospheric pressure difference across the North Sea. J Geophys Res 106(C9): 19731-19744

Heino R and 10 others (1999) Progress in the study of climatic extremes in northern and central Europe. Clim Change 42:151-181

Hurell JW, Folland CK (2002) A change in the summer atmospheric circulation over North Atlantic. Exchange 25:1-3

IPCC (2001) Climate Change: the scientific basis. Contribution of Working Group I to the Third Assessment Report of the Intergovernmental Panel on Climate Change. Houghton JT et al. (eds). Cambridge University Press, Cambridge

Jacobeit J, Jönsson P, Bärring L, Beck C, Ekström M (2001) Zonal indices for Europe 1780-1995 and running correlation with temperature. Clim Change 48:219-241

Jacobeit J, Wanner H, Luterbacher J, Beck C, Philipp A, Sturm K (2003) Atmospheric circulation variability in the North-Atlantic-European area since the mid-seventeenth century. Clim Dyn 20:341-352

Jevrejeva S (2001) Severity of winter seasons in the northern Baltic Sea between 1529 and 1990: reconstruction and analysis. Clim Res 17:55-62

Jones PD and 21 others (1999) Monthly mean pressure reconstructions for Europe for the 1780-1995 period. Int J Climatol 19:347-364

Karlén W, Källén E, Rodhe H, Backman J (1999) Man-made versus natural climate change. Ambio 28:376-377

Koslowski G, Glaser R (1999) Variations in reconstructed winter severity in the western Baltic from 1501 to 1995, and their implications from the North Atlantic Oscillation. Clim Change 41:175-191

Lamb HH (1950) Types and spells of weather around the year in the British Isles. Q J R Meteorol Soc 76:393-438

Moberg A, Bergström H (1997) Homogenisation of Swedish temperature data. Part III: The long temperature records from Uppsala and Stockholm. Int J Climatol 17:667-699

Moberg A, Bergström H, Krigsman JR, Svanered O (2002) Daily air temperature and pressure series for Stockholm (1765-1998). Clim Change 53:171-212

Omstedt A, Chen D (2001) Influence of atmospheric circulation on the maximum ice extent in the Baltic Sea. J Geophys Res 106(C3):4493-4500

Omstedt A, Rutgersson A (2000) Closing the water and heat cycles of the Baltic Sea. Meteorol Z 9 (1):59-66

Räisänen J, Alexandersson H (2003) A probabilistic view on recent and near future climate change in Sweden. Tellus 55A(2):113-125 
Samuelsson M, Stigebrandt A (1996) Main characteristics of the long-term sea level variability in the Baltic Sea. Tellus 48A:672-683

Seinä A, Palosuo E (1993) The classification of the maximum annual extent of ice cover in the Baltic Sea 1720-1992. Meri 20:5-20 (in Finnish)

Stewart I (2003) Regime change in meteorology. Nature 422: $571-573$

Tinz B (1996) On the relation between annual maximum

Editorial responsibility: Hans von Storch, Geesthacht, Germany extent of ice cover in the Baltic Sea and sea level pressure as well as air temperature field. Geophysica 32:319-341

Winsor P, Rodhe J,Omstedt A (2001) Baltic Sea ocean climate: an analysis of $100 \mathrm{yr}$ of hydrographic data with focus on the freshwater budget. Clim Res 18:5-15

Wroblewski A (1998) The effect of the North Sea on oscillations of the mean monthly sea levels in the Baltic Sea. Cont Shelf Res 18:5001-514

Submitted: June 16, 2003; Accepted: October 17, 2003

Proofs received from author(s): December 1, 2003 